\title{
Analysis of chemical composition of the cube-shaped phase in the Al-Mg-Si alloy by EFTEM and SLEEM
}

\author{
K. Matsuda*, Y. Ishida**, I. Mullerova***, L. Frank***, S. Ikeno* \\ *Faculty of Engineering, Toyama University, 3190, Gofuku, Toyama, 930-8555, Japan \\ **Graduate student, Toyama University, 3190, Gofuku, Toyama, 930-8555, Japan \\ *** Institute of Scientific Instruments ASCR, CZ-61264 Brno, Czech Republic
}

It is well known that the $\beta-\mathrm{Mg}_{2} \mathrm{Si}$ phase is the equilibrium one in the Al-Mg-Si alloy. Several authors have also reported the cube-shaped phase in the Al-Mg-Si alloy with excess $\mathrm{Mg}$ and in quasi-binary alloys and discussed whether it is a precursor of the $\beta$-phase or not [1-2]. Application of the energy filtering TEM (EFTEM) to quantifying chemical composition of fine precipitates is very successful [3] and for the case of precipitates in Al-Mg-Si alloys this has been reported in our recent works [4]. Also the scanning low energy electron microscopy (SLEEM) is a useful way to obtaining information about the sample surface [5]. In this study the cube-shaped phase (cubephase) in Al-Mg-Si with excess Mg was investigated by EFTEM and SLEEM techniques in order to determine the crystal structure and its chemical composition.

In the present experiments, samples of the Al-1.0mass $\% \mathrm{Mg}_{2} \mathrm{Si}-0.4 \mathrm{mass} \% \mathrm{Mg}$ (excess $\mathrm{Mg}$ ) alloy were solution heat-treated at $848 \mathrm{~K}$ for $3.6 \mathrm{ks}$ and quenched in chilled water at $277 \mathrm{~K}$. The aging process was performed at $623 \mathrm{~K}$. TEM specimens were prepared by conventional electrolytic polishing method and studied in an EFTEM (JEOL-4010T) equipped with a post-column energy filter and EDS, and operated at $400 \mathrm{kV}$. Elemental maps were obtained by using the three-window method with higher energy loss electrons. SLEEM detector was manufactured in ISI Brno and installed into the SEM (Hitachi S-3500H).

Fig. 1(a) shows the zero-loss image of the cube-phase in an excess $\mathrm{Mg}$ alloy aged at $623 \mathrm{~K}$ for $6 \mathrm{ks}$. It is about $60 \mathrm{~nm}$ in size and its sides were found parallel to the [100] and [010] directions of the Al-matrix. Fig. 1(b) and (c) are the Mg-K and Si-K maps. Fig. 1(d) and (e) are the quantitative results calculated from intensities of these elemental maps [3]. The calculated ratio of $\mathrm{Mg} / \mathrm{Si}$ was 3.09 instead of 2.0 and this result was approximately confirmed by the EDS analysis. Fig. 2(a) shows the SEM image at $20 \mathrm{keV}$. The precipitates may be identified at low contrast but their shapes cannot be recognized. In Fig. 2(b), acquired in the SLEEM mode at a landing energy of $1.6 \mathrm{keV}$, the precipitates are not only well observable in their correct shapes, but they can be even sorted according to additional details. The EDS analysis, performed on precipitates marked with 1 to 4, resulted for \#1 and \#2 in the $\mathrm{Mg} / \mathrm{Si}$ ratio near 2.0 but for \#3 and \#4 it grew near to 3 . This result supported the EFTEM data and confirmed the SLEEM imaging sensitive to differences in chemical composition of tiny precipitates. 
References

[1] H.Westengen and N.Ryum, Z. Metallkde. 70 (1979) 528.

[2] Y.Ohmori, L.C.Doman, Y.Matsuura, S.Kobayashi and K.Nakai, Mater. Trans. 42 (2001) 2567.

[3] R.F.Egerton: Electron Energy-Loss Spectroscopy in Electron Microscopy, 2nd ed., Plenum Press, 1996.

[4] K. Matsuda et al., Scripta Mater., 47 (2002) 833.

[5] I. Mullerova and L. Frank, Advances in Imaging and Electron Physics 128 (2003) 309.
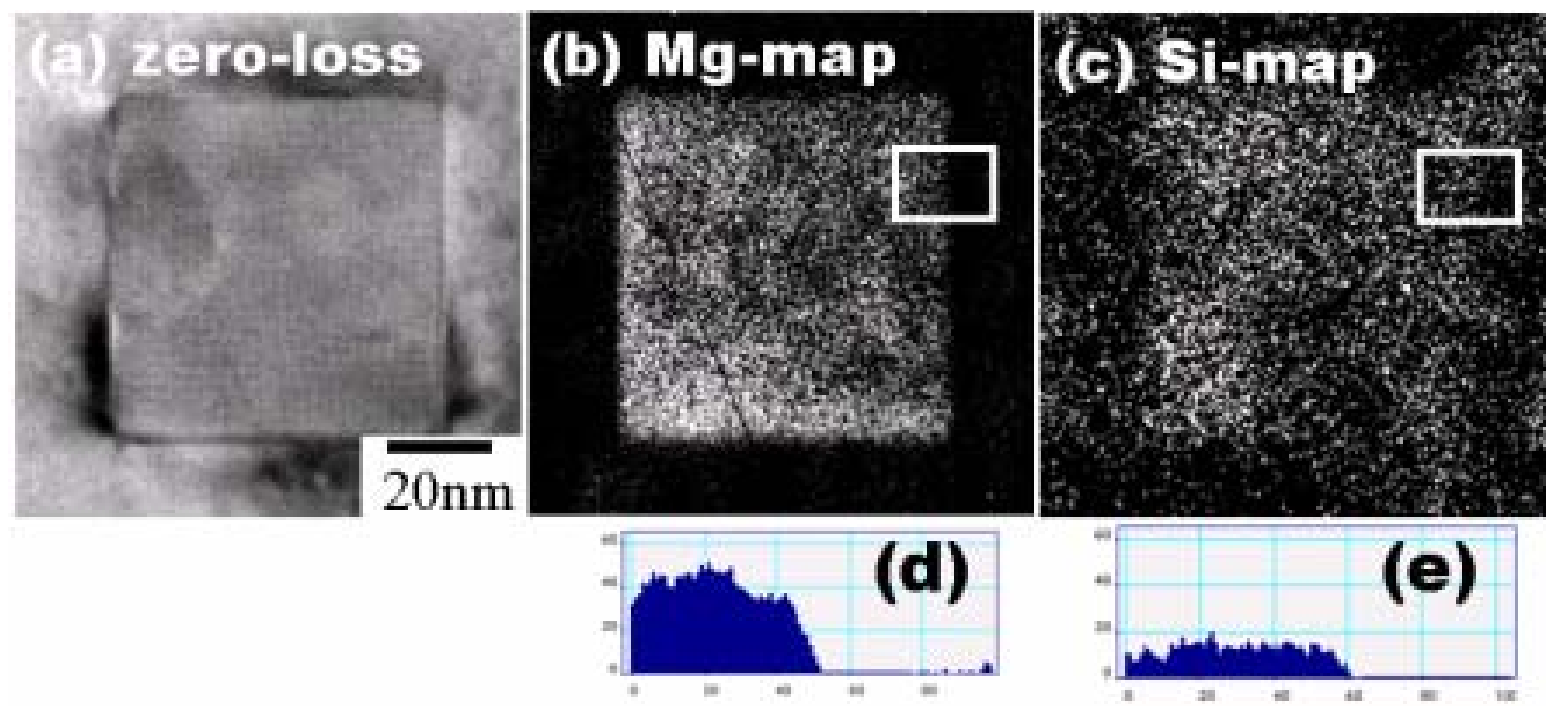

Fig. 1. EFTEM images obtained from the cube-phase in an excess $\mathrm{Mg}$ alloy aged at $623 \mathrm{~K}$ for $6 \mathrm{ks}$ : (a) zero-loss image; (b) Mg-K (1305eV) and (c) Si-K (1839eV) maps; (d) and (e) are calculated quantitative profiles from intensities in (b) and (c), respectively, showing the numbers of $\mathrm{Mg}$ or $\mathrm{Si}$ atoms per unit volume.

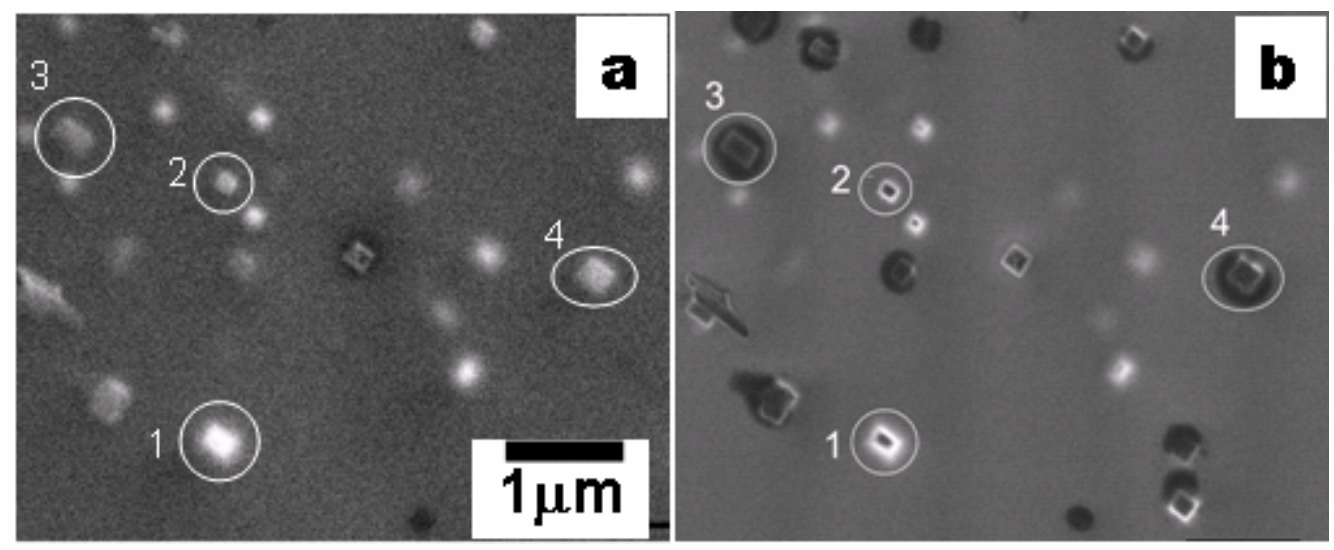

Fig. 2. SLEEM image of the cube-phase in an excess Mg alloy: (a) SEM image (20 keV), and (b) SLEEM image (1.6 keV). 